\title{
The 9 Stress-free Stitches Technique: Feasibility and Outcomes of a New Technique for Aortic Valve Replacement
}

\author{
Apicella G*, El Nakadi B, Joris M \\ Department of Cardio-thoracic Surgery, Hospital Civil Marie Curie, Charleroi, Belgium
}

Copyright(C2017 by authors, all rights reserved. Authors agree that this article remains permanently open access under the terms of the Creative Commons Attribution License 4.0 International License

\begin{abstract}
Objective: This study aims to evaluate the feasibility and short-term outcomes of a novel surgical technique, named 'the nine stress-free stitches technique' for aortic valve replacement (AVR) in patients with aortic valve disease. Methods: From May 2013 to October 2015, 63 consecutive patients underwent aortic valve replacement with the nine stress-free stitches technique, using the Magna Ease bioprosthesis (Edwards Lifesciences, Irvine, CA, USA). Demographics, clinical and echocardiographic data were collected retrospectively. The primary endpoints were paravalvular leak, pacemaker insertion, and mortality. Results: There was one case of moderate paravalvular leak. 2 patients required permanent pacemaker implantation. In-Hospital mortality was $6.3 \%$. All deaths were in redo or combined procedure patients. Conclusion: This preliminary series demonstrates that the nine stress-free stitches technique is an acceptable technique for aortic valve replacement. The potential advantages are reduced ischemic time, especially in combined procedures, with easy replication.
\end{abstract}

Keywords Aortic Valve Replacement, New Method, Stented Bioprostheses

\section{Introduction}

Aortic valve replacement is an established technique performed in patients with severe aortic valve disease.

Idiopathic senile degeneration with sclerosis and calcification of the aortic valve has become the most frequent type of valve disease in Europe and North America due to its ageing population $(2 \%-7 \%$ of the population is over the age of 65). Greater mechanical stress with age and risk factors such as hypertension, smoking, diabetes, and hypercholesterolaemia contribute to $2 \%-4 \%$ of adults $>65$ years of age suffering from acquired AS.

Symptomatic patients with severe aortic stenosis can develop major adverse cardiac events that have been reported as $80 \%$ at 1 year, $63 \%$ at 2 years, and $25 \%$ at 5 years. Surgical aortic valve replacement (AVR) is currently the gold-standard treatment for symptomatic aortic stenosis. Excellent short- and long-term outcomes have been reported. (with a mortality rate of $2.6 \%$ )

Despite these results, advancing age, an increasing presence of comorbidities and increased surgical risk in the patient population has stimulated the development of less invasive procedures that may reduce morbidity and mortality.

Transcatheter aortic valve implantation has provided a valid short-term alternative in high-risk patients, reducing 1 - and 3-year mortality by at least one third compared with standard medical treatment.

The implantation of sutureless valves has also been proven to be safe and efficient, however, the long-term durability of transcatheter aortic valve replacement and sutureless valve prostheses is not yet known. ${ }^{1-14}$

We aimed to create a technique that facilitates the replacement of aortic valve, shorten operating time, and avoid the complications of prolonged cardiopulmonary bypass (CPB) and aortic cross-clamp (ACC) times; while using the standard material.

The 9 stress-free stitches technique for aortic valve replacement is a new method, developed in our Cardio-thoracic surgery department.

In this technique, we used nine interrupted stitches for all valve sizes, owing to the geometry and design of the bioprosthesis valve and the careful placement of each suture; nine stitches were enough to ensure natural sealing of the valve to the aortic annulus.

\section{Methods}

This is a retrospective, observational study, with a cohort of consecutive patients.

From May 2013 to October 2015, 63 patients with severe 
aortic stenosis underwent aortic valve replacement with the 9 stress-free stitches technique. Pre-operative patients' characteristics comparing patients undergoing isolated or redo/combined procedure are summarized in table 1 .

Data was retrospectively obtained from our database or the referring cardiologist. There were no differences between the two groups in age, gender, hypertension, COPD, smoking, peripheral vascular disease, pre-existing AF, previous stroke and TIA or conduction disorders. The redo and combined procedure group patients were more likely to have diabetes $(27 \%$ vs. $57 \%, \mathrm{P}>0.05)$, and chronic kidney disease $(9 \%$ vs. $20 \%, \mathrm{P}<03)$, but the isolated procedure group patients were more likely to have a bicuspid valve. Patients in the redo/combined procedure group had a significantly higher incidence of hyperlipidemia and coronary artery disease.

Transthoracic echocardiogram (TEE) was performed before discharge and 1 and 10 months after discharge.

Table 1. Pre-operative patients' characteristics

\begin{tabular}{|c|c|c|c|}
\hline Variable & isolated AVR $(n=33)$ & $\begin{array}{l}\text { combined/redo procedure } \\
(\mathrm{n}=30)\end{array}$ & P-value \\
\hline Age mean $+/-$ SD & $75.6+/-6.6$ & $74+/-8.7$ & 0.3 \\
\hline Male Gender & $14(42 \%)$ & $17(57 \%)$ & $>0.3$ \\
\hline Female Gender & $19(58 \%)$ & $13(43 \%)$ & $>0.3$ \\
\hline \multicolumn{4}{|l|}{ Comorbidities } \\
\hline Hypertension & $29(88 \%)$ & $27(90 \%)$ & $>0.9$ \\
\hline Diabetes & $9(27 \%)$ & $17(57 \%)$ & $>0.05$ \\
\hline Hyperlipidemia & $12(36 \%)$ & $24(80 \%)$ & $<0.05$ \\
\hline Smoking & $10(30 \%)$ & $10(33 \%)$ & $>0.5$ \\
\hline Severe COPD & $5(15 \%)$ & $2(6.6 \%)$ & $>0.3$ \\
\hline Coronary artery disease & $1(3 \%)$ & $10(33 \%)$ & $<0.01$ \\
\hline Hystory of stroke/TIA & $3(9 \%)$ & $3(10 \%)$ & $>0.9$ \\
\hline Peripheral vascular disease & $1(3 \%)$ & $4(13 \%)$ & $<0.2$ \\
\hline Chronic kidney disease & $3(9 \%)$ & $6(20 \%)$ & $<0.3$ \\
\hline Previous cardiac surgery & 0 & $3(10 \%)$ & $>0.05$ \\
\hline \multicolumn{4}{|l|}{ Pre-operative rythm } \\
\hline Atrial fribtillation & $4(12 \%)$ & $5(16.6 \%)$ & $>0.5$ \\
\hline Pacemaker & $2(6 \%)$ & $1(3.3 \%)$ & $>0.5$ \\
\hline Minor conduction disorders & $6(18 \%)$ & $6(20 \%)$ & $>0.5$ \\
\hline Log Euroscore, mean +/- SD \% & $7.8+/-6$ & $10.7+/-10.5$ & 0.1 \\
\hline Additive euroscore +/- SD & $8.8+/-10$ & $7.9+/-2.3$ & 0.5 \\
\hline Bicuspide Aortic valve & $9(27 \%)$ & $5(16 \%)$ & $>0.1$ \\
\hline \multicolumn{4}{|l|}{ Pre-operative TTE } \\
\hline Peak transaortic gradient, mean +/- SD (mmhg) & $74+/-20$ & $69.8+/-23.5$ & 0.3 \\
\hline Mean transaortic gradient,mean +/- SD (mmhg) & $45.9+/-13$ & $42.7+/-16.7$ & 0.3 \\
\hline Speed +/- SD (m/sec) & $4+/-0.9$ & $3.9+/-0.8$ & 0.5 \\
\hline Surface pre-operative & $0.77+/-0.1$ & $0.8+/-0.2$ & 0.3 \\
\hline
\end{tabular}


Surgical technique:

The same surgeon performed all procedures. The Edwards Magna Ease bio-prosthesis valve was used in all cases.

The operation was performed using the classic median sternotomy approach $(n=30,47 \%)$ for redo and combined procedures, or a less invasive approach (partial sternotomy) $(\mathrm{n}=33,52 \%)$, for isolated replacements.

In this technique a limited midline skin incision was performed, extending $7 \mathrm{~cm}$ from the angle of Louis (fig.1), then the sternum was almost totally divided using an oscillating saw. The interclavicular ligament and the xiphisternum were left intact to give post-operative stability.

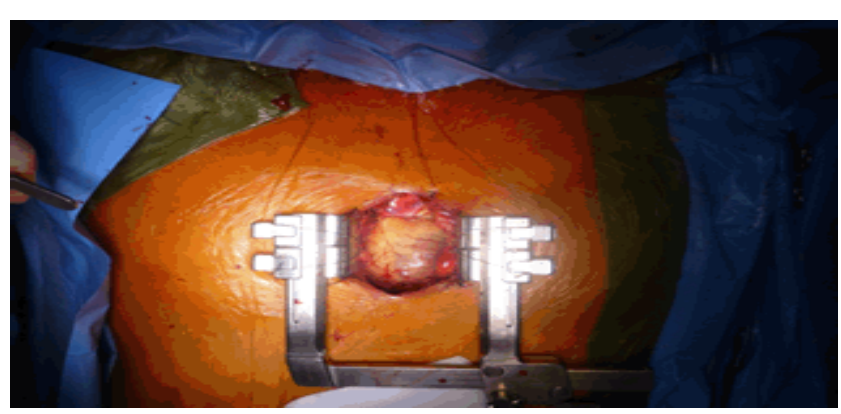

Figure.1. Minimal incision approach: a $7 \mathrm{~cm}$ midline skin incision from the angle of Louis towards the xiphisternum

Cardiopulmonary bypass was established by aortic and atrial cannulation.

A left ventricular vent was inserted via the right superior pulmonary vein (Fig.2).

Antegrade cold blood cardioplegia was usually repeated every $20-30 \mathrm{~min}$ and immediately in the event of ECG activity.
An S shape aortotomy was made.

Traction sutures were placed through the top of each commissure and clipped to the surgical drapes.

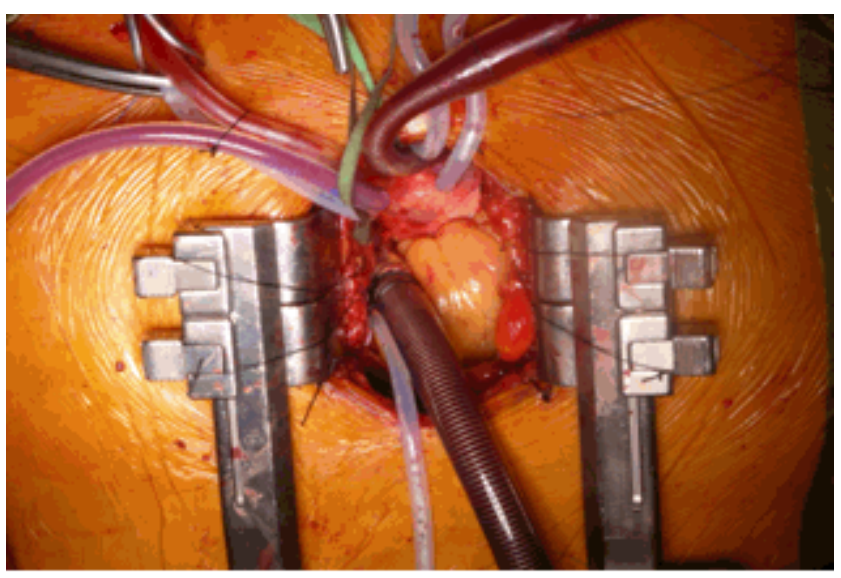

Figure.2. $\mathrm{CPB}$ established by aortic and atrial cannulation and a left ventricular vent via the right superior pulmonary vein

Three mattress stitches with pledgets were placed at the level of the three commissures with the pledgets in the sub-annular position. The stitches were placed sub-annularly, to create a neo-annulus where the prosthesis could sit and eliminate the dead space between the prosthetic valve and the patient's aorta to reduce leakage. Then 6 large everting $U$ stitches were placed supra-annularly; 2 for each leaflet. These stitches were intended to strengthen and marginalize the annulus below the prosthesis.

The sutures were then passed through the valve sewing ring as close as possible to the valve stent (Fig.3).

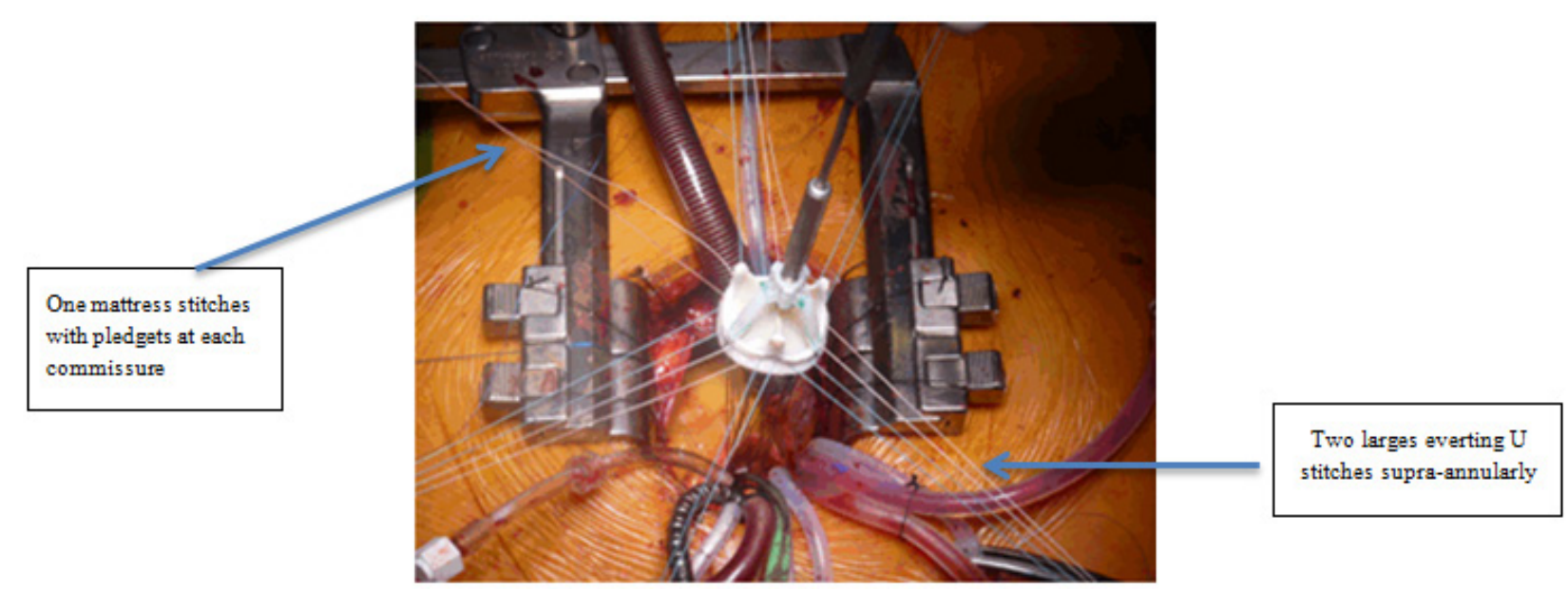

Figure 3. Three mattress stitches with pledgets at the level of the three commissures and 6 large everting U stitches supra-annularly for a total of 9 stitches. The sutures passed through the valve sewing ring as close as possible to the valve stent. 
The valve was located above the aortic annulus, and the sutures were tied very gently to obtain a "stress-free fixation."

The sutures at each of the three commissures were tied first: the stitch at the commissure between the right and left coronary ostia was tied first, then the one at the commissure between the left ostium and the non-coronary leaflets, and finally the suture at the commissure between the right ostium and non-coronary cusp.

The knots at the commissures were not tied tight; they just needed to ensure that the valve sat appropriately on the neo-annulus.

The remaining stitches were tied beginning on either side of the commissure between the left and the right coronary ostia.

This resulted in a true "supra-annular" position of the bioprosthesis using the sewing ring for a pressure dependent sealing.

\section{Statistical Analysis}

Continuous values are expressed as mean $+/$ - standard deviation (SD) and categorical variables are displayed as percentages.

For comparison of qualitative variables, the Chi-square test was used.
A p-value less than 0.05 was considered significant.

\section{Results}

Operative data was collected during the operation in a common database.

In the redo and combined group procedure, the operative approach used the classic median sternotomy, while in the isolated procedure group employed the limited skin incision and partial sternotomy.

There was no conversion of a small incision into a full sternotomy.

There was no significant difference in valve size implanted. In the redo and combined group, a bigger size prosthesis tended to be used.

Coronary artery bypass grafting (CABG) was the most common other procedure performed at the time of aortic valve replacement in the redo/combined procedure group. The remaining concomitant procedures included simplified MAZE, ascending aorta replacement, mitral valve replacement, and mitral valve repair.

$\mathrm{CPB}$ times and ACC times were longer in the redo/combined procedure group. The mean duration of ACC and CPB times was $57+/-8.9$ min and $81+/-14.7$ min respectively for single procedures; $100+/-26.7 \mathrm{~min}$ and $129.5+/-35$ min respectively for combined and redo procedures. (Table 2)

Table 2. Intra-operative data

\begin{tabular}{|c|c|c|c|}
\hline Variable & Isolated AVR & Combined/redo procedure & P-value \\
\hline \multicolumn{4}{|c|}{ Surgical approach } \\
\hline Sternotomy & 0 & $30(100 \%)$ & $<0.001$ \\
\hline Ministernotomy & $33(100 \%)$ & 0 & $<0.001$ \\
\hline CABG & & $22(73 \%)$ & \\
\hline \multicolumn{2}{|c|}{ Simplified Maze } & $3(10 \%)$ & \\
\hline \multicolumn{2}{|c|}{ Ascending Ao replacement } & $3(10 \%)$ & \\
\hline MVR & & $2(6.6 \%)$ & \\
\hline $\mathrm{MVr}$ & & $1(3.3 \%)$ & \\
\hline \multicolumn{2}{|c|}{ Redo procedures } & $3(10 \%)$ & \\
\hline \multicolumn{4}{|c|}{ Prosthesis size } \\
\hline Extra-small (19mm) & $5(15 \%)$ & $1(3,3 \%)$ & $>0.1$ \\
\hline Small (21mm) & $6(18 \%)$ & $8(26 \%)$ & $>0.3$ \\
\hline Medium (23mm) & $13(39 \%)$ & $9(30 \%)$ & $>0.5$ \\
\hline Large $(25 \mathrm{~mm})$ & $9(27 \%)$ & $10(33 \%)$ & $>0.5$ \\
\hline Extra-large $(27 \mathrm{~mm})$ & 0 & $2(6,6 \%)$ & $>0.1$ \\
\hline ACC time, mean +/- SD (min) & $57+/-8.9 \min$ & $100+/-26.7 \mathrm{~min}$ & $<0.001$ \\
\hline CPB time, mean +/-SD (min) & $81+/-14.7 \mathrm{~min}$ & $129.5+/-35 \mathrm{~min}$ & $<0.001$ \\
\hline
\end{tabular}

ACC Aortic cross clamp CPB Cardiopulmonary bypass SD Standard deviation

AVR Aortic valve replacement CABG Coronary artery bypass surgery

MVR Mitral valve replacement MVr Mitral valve repair 
Intraoperative TEE revealed satisfactory hemodynamic performance of the valve prostheses, without any significant paravalvular regurgitation, in all cases except in one patient.

There were 4 deaths $(6.3 \%)$, all due to multiple organ failure, all in the combined and redo procedure group.

One patient without preoperative conduction disorders, operated for acute aortic dissection, developed per-operative atrioventricular (AV) block. He died on the $4^{\text {th }}$ postoperative day. 2 patients showed third-degree AV block, one had a pacemaker implantation, but the pacemaker check after 2 months showed a normal conduction; the other one resolved after stopping beta blockers.

4 patients presented new minor conduction disorders: 6 patients displayed a first degree AV block, 6 patients had a left bundle branch block (LBBB) (4 complete and 2 partial), and 2 patients had a right bundle branch block (RBBB)
(1 complete and 1 partial). (Table 3 )

TEE was routinely performed 8.9 +/- 7.5 days post-operatively in all patients. (Table 4)

The mean trans-aortic valve gradient was $12.6+/-4$ $\mathrm{mmHg}$ for the patients in the isolated AVR group and 14.4 $+/-3.4 \mathrm{mmHg}$ in the redo and combined procedure group. The short and middle term result of post-operative echocardiogram revealed no significant difference about the gradients or paravalvular leak between the two groups of patients confirming the success of the operation in both groups.

There was one moderate paravalvular leak without clinical consequences; this complication occurred in the first patient who had a bicuspid aortic valve.

Unfortunately, only 17 patients in the combined and redo procedure group and 24 patients in the isolated AVR group attended the TEE at the last follow up. (Table 4)

Table 3. Post-operative outcomes

\begin{tabular}{|c|c|c|c|}
\hline Variable & Single AVR $(n=33)$ & Combined/redo procedures $(n=30)$ & P-value \\
\hline In-Hospital Mortality & 0 & $4(13 \%)$ & 0.02 \\
\hline Hospital stay, mean $+/-$ SD & $14.7+/-6.9$ & $15+/-8.1$ & 0.5 \\
\hline Mean ICU length of stay, mean +/- SD & $2.9+/-2.2$ & $3.7+/-4.1$ & 0.3 \\
\hline Valve migration & 0 & 0 & \\
\hline Endocarditis & 0 & 0 & \\
\hline Stroke & $1(3 \%)$ & 0 & $>0.3$ \\
\hline Acute Kidney injury & $5(15 \%)$ & $9(30 \%)$ & $>0.2$ \\
\hline Dialysis & 0 & $3(10 \%)$ & $>0.05$ \\
\hline Delirium & $4(12 \%)$ & $7(23 \%)$ & $>0, .2$ \\
\hline Bleeding requiring re-operation & $1(3 \%)$ & $1(3.3 \%)$ & $>0.9$ \\
\hline Myocardial infarction & 0 & 0 & \\
\hline Atrial Fibrillation & $15(45 \%)$ & $10(33 \%)$ & $>0.3$ \\
\hline \multicolumn{4}{|c|}{ Conduction disorders } \\
\hline Pacemaker & $1 *(3 \%)$ & $1 * *(3.3 \%)$ & $>0.9$ \\
\hline \multicolumn{4}{|c|}{ Minor disorders conduction } \\
\hline 1st degre AVB & $4(12 \%)$ & $1(3.3 \%)$ & $>0.2$ \\
\hline 2nd degre AVB & 0 & 0 & \\
\hline Partial LBBB & $1(3 \%)$ & $1(3.3 \%)$ & $>0.9$ \\
\hline Complete LBBB & $1(3 \%)$ & $2(6.6 \%)$ & $>0.5$ \\
\hline Partial RBBB & $1(3 \%)$ & 0 & $>0.3$ \\
\hline Complete RBBB & $1(3 \%)$ & 0 & $>0.3$ \\
\hline Pneumopathy & $3(9 \%)$ & 0 & $>0.05$ \\
\hline Thrombopenia & $7(21 \%)$ & 0 & $>0.01$ \\
\hline Cardiogenic shock & 0 & $6(20 \%)$ & $>0.01$ \\
\hline
\end{tabular}

SD Standard deviation AVR Aortic valve replacement AVB Atrioventricular block

LBBB Left bundle branch block RBBB Right bundle branch block

*The pacemaker's control after 2 months showed a normal conduction

** The patient died at the 4th day post-operative (emergency operation for aortic dissection) 
Table 4. Post-operative TTE

\begin{tabular}{|c|c|c|c|}
\hline Variable & Isolated AVR & Combined/redo procedure & P-Value \\
\hline \multicolumn{4}{|l|}{ Pre-discharge TTE } \\
\hline Peak Transaortic gradient, mean +/- SD (mmHg) & $24+/-8$ & $21.3+/-9.4$ & 0.2 \\
\hline Mean transaortic gradient, mean $+/-\mathrm{SD}(\mathrm{mmHg})$ & $12.6+/-4$ & $14.4+/-3.4$ & 0.1 \\
\hline Speed, mean $+/-\mathrm{SD}(\mathrm{m} / \mathrm{sec})$ & $2.4+/-0.3$ & $2.3+/-0.5$ & 0.3 \\
\hline \multicolumn{4}{|l|}{ Paravalvular Leak } \\
\hline Mild & 0 & 0 & \\
\hline Moderate-Severe & $1 *(3 \%)$ & 0 & 0.3 \\
\hline \multicolumn{4}{|l|}{ Post-dicharge TTE } \\
\hline Peak Transaortic gradient, mean +/- SD (mmhg) & $24.6+/-8.9$ & $21.6+/-8,4$ & 0.2 \\
\hline Mean transaortic gradient, mean $+/-\mathrm{SD}(\mathrm{mmhg})$ & $13.2+/-5.5$ & $12.3+/-3.6$ & 0.5 \\
\hline Speed, mean $+/-\mathrm{SD}(\mathrm{m} / \mathrm{sec})$ & $2+/-0$ & $2+/-0$ & 0 \\
\hline \multicolumn{4}{|l|}{ Paravalvular Leak } \\
\hline Mild & 0 & 0 & \\
\hline Moderate-Severe & $1 *(3 \%)$ & 0 & $>0.3$ \\
\hline
\end{tabular}

SD Standard deviation AVR Aortic valve replacement

*First patient of the series, bicuspid aortic valve

There was no migration or structural damage to the prosthetic valve.

None of the patients required a conversion of the 9 stress-free stitches technique into a conventional replacement procedure during the operation, and none of the patients required re-operation for valve failure or paravalvular leak.

One-year mortality was $6.7 \%$, un-related to the AVR.

\section{Discussion}

Elderly patients referred for AVR often have multiple comorbidities and new implantation techniques, like sutureless or rapid deployment valves, have been developed to minimize the surgical risk ${ }^{15-17}$.

We wanted to create a standardized and simplified procedure to reduce the $\mathrm{ACC}$ and $\mathrm{CBP}$ time while maintaining the same efficacy, quality, and safety of a conventional approach.

We report a series of AVR cases using the 9 stress-free stitches technique in patients with severe aortic stenosis.

The peculiarity of our method is that suture knots at two of the three commissures are tied very gently, they just need to ensure that the valve will sit appropriately; in fact, one is passed in the muscular septum and the other one near the His bundle so they cannot be tied too tight. They just need to create a new annulus where the prosthetic valve sits naturally.

The 6 U-sutures placed supra-annularly, are intended to give a better support on to a fragile annulus. They help avoid protrusion of the residual annulus we see with sub-annular U-stitches.

With this technique, it is important to pass the stitches near the metallic ring at the base of the valve, to avoid deforming the sewing ring; this decreases the risk of paravalvular leak.
Considerable care needs to be taken to ensure that the biological prosthesis is implanted with perfect sealing at the natural annulus, using the pressure environment of the valve and the design of the prosthetic ring to avoid a para-prosthetic leak.

Compared to what has been reported in the literature, we don't have an increased incidence of leaks despite the limited number of stitches used to implant the valve.

In our series there was one moderate paravalvular leak without clinical consequences. This complication occurred in the first patient who had a bicuspid aortic valve.

According to the literature the incidence of paravalvular leak in patients undergoing aortic valve replacement is $2-10 \%$ and 1 to $5 \%$ of patients have hemodynamic repercussions and become symptomatic.

The risk of developing an early paravalvular leak is increased by technical difficulties such as annular calcification, suturing technique, prosthetic size, and shape $^{18-19}$.

To decrease these risks we created a new annulus where the prosthesis can sit, and we used the soft sewing ring of the bioprosthesis to model against the patient aorta and ensure the sealing; choosing the right sizing of the prosthesis is a fundamental step of our technique; in the case of the bicuspid valve we center the geometry of the bioprosthesis to the fusion commissure.

In our series, 33 patients underwent an isolated AVR surgery through a small skin incision without conversion.

Compared to a full sternotomy or a J-ministernotomy, our small incision gives a better operative position and an improved cosmetic appearance.

Compared to the literature, our ACC time is equal if not shorter than conventional replacement through full sternotomy or ministernotomy ${ }^{7,9,12,13}$ (Table 5 - 6). This is due to the association of a small skin incision giving a good exposure to the aortic valve with a fast implanting technique. 
Table 5. Comparisons of isolated AVR through conventional replacement to the 9 stress-free stitches technique

\begin{tabular}{|c|c|c|c|c|c|}
\hline Author & Technique & Prosthesis & Patients & ACC Time* & P-value \\
\hline Glauber et all & FS (CR) & MP or BP & 336 & $71+/-24$ & $<\mathbf{0 . 0 1}$ \\
\hline Bakir et all & FS (CR) & MP or BP & 274 & $69.5+/-16.6$ & $<\boldsymbol{0 . 0 0 1}$ \\
\hline Mihalijevic et all & FS (CR) & MP or BP & 516 & $86(30-252)$ & $<\mathbf{0 . 0 0 0 5}$ \\
\hline Shehada et all & FS (pledgets U-stitches) & NG & 585 & $64.3+/-19.8$ & $<\boldsymbol{0 . 0 5}$ \\
\hline Furukawa et all & FS (CR) & MP or BP & 404 & $54+/-17$ & $<0.5$ \\
\hline Forcillo et all & FS (CR) & BP & 319 & $85(66-113)$ & $<\boldsymbol{0 . 0 0 0 5}$ \\
\hline Our series & 9 stitches technique (MS) & Edwards Magna Ease & 33 & $57+/-8.956(45-81)$ & $/$ \\
\hline
\end{tabular}

ACC Aortic cross clamp CR Conventional replacement FS Full sternotomy MS Ministernotomy

MP Mechanical prosthesis BP Biological prosthesis NG Not given

*Mean + /- standard deviation (SD) - Median $(\min -\max )$

Table 6. Comparisons of isolated AVR through ministernotomy to the 9 stress-free stitches technique

\begin{tabular}{|c|c|c|c|c|c|}
\hline Author & Technique & Prosthesis & Patients & ACC Time* & P-value \\
\hline Fattouch et all & Ministernotomy (RS) & MP or BP & 854 & $62.4+/-23.7$ & $<0.2$ \\
\hline Mihalijevic et all & Ministernotomy (CR) & MP or BP & 526 & $77(21-291)$ & $<\boldsymbol{0 . 0 5}$ \\
\hline Raja et all & Ministernotomy & NG & 585 & $65.6+/-18.4$ & $<\mathbf{0 . 0 1}$ \\
\hline Furukawa et all & Ministernotomy & MP or BP & 404 & $59+/-14$ & $<0.5$ \\
\hline Bakir et all & Ministernotomy (CR) & MP or BP & 232 & $61.8+/-16.6$ & $<0.2$ \\
\hline Our series & 9 stitches technique (MS) & Edwards Magna Ease & 33 & $57+/-8.956(45-81)$ & $/$ \\
\hline
\end{tabular}

ACC Aortic cross clamp RS Running suture CR Conventional replacement MS Ministernotomy NG Not given MP Mechanical prosthesis BP Biological prosthesis

*Mean $+/$ - standard deviation (SD) - Median $(\min -\max )$

Table 7. Comparisons of isolated AVR through sutureless or rapid deployment technique to the 9 stress-free stitches technique

\begin{tabular}{|c|c|c|c|c|c|}
\hline Author & Technique & Prosthesis & Patients & ACC Time* $^{*}$ & P-value \\
\hline Santarpino et all & Sutureless (MS) & Perceval S & 72 & $40+/-13$ & $<\mathbf{0 . 0 0 1}$ \\
\hline Dalen et all & Sutureless (MS) & Perceval S & 189 & $41+/-18$ & $<\mathbf{0 . 0 0 1}$ \\
\hline Dalen et all & Sutureless (FS) & Perceval S & 78 & $43+/-36$ & $<\mathbf{0 . 0 5}$ \\
\hline Forcillo et all & Sutureless (FS or MS) & Perceval S & 76 & $60(49-80)$ & 0.25 \\
\hline \multirow{2}{*}{ Wahlers et all } & RD & Edwards intuity & 158 & $46.1+/-26.4$ & $<\mathbf{0 . 0 2}$ \\
\cline { 2 - 6 } & (FS or MS) & \multirow{2}{*}{ Edwards Magna Ease } & 33 & $57+/-8.9$ & $56(45-81)$ \\
\hline
\end{tabular}

ACC Aortic cross clamp FS Full sternotomy MS Ministernotomy RD Rapid deployment

*Mean $+/$ - standard deviation $\quad$ (SD) - Median (min - max)

Minimally invasive approach data is quite controversial: Furukawa et al. have shown longer ACC times compared to full sternotomy as a consequence of more technical difficulties caused by limited heart exposure ${ }^{7}$.

On the other hand, Bakir et al. reported decreased ACC and $\mathrm{CPB}$ times when comparing ministernotomy to full sternotomy ${ }^{10}$ (Table 6).

Santarpino et al., demonstrated a mean ACC time of 40 +/- 13 min when combining a ministernotomy approach with sutureless valve technology ${ }^{16}$ (Table 7).

When compared to sutureless and rapid deployment valve implantation, our ACC times are significantly longer, but our rate of pacemaker implantation and paravalvular leak is lower.

Out of a total of 14 patients with bicuspid aortic valve, we had just one moderate paravalvular leak in the very first patient of the series.

In the articles by Nguyen et al. published in 2015 that studied the feasibility of sutureless technique in patients with bicuspid aortic valves, the results describe a $20 \%$ rate of permanent pacemaker implantation and $12 \%$ of paravalvular leak at the pre-discharge $\mathrm{TTE}^{20}$ (Table 8). 
Table 8. Comparison of PV leak and PM implantation between the sutureless or rapid deployment technique and the 9 stress-free stitches technique

\begin{tabular}{|c|c|c|c|c|c|c|}
\hline Author & Technique & Patients & PV Leak & P-value & PM implantation & P-value \\
\hline Santarpino et all & Sutureless (PS) & 72 & 0 & $<0.3$ & $4(5.5 \%)$ & $<0.2$ \\
\hline Dalen et all & Sutureless (PS) & 189 & $5(2.6 \%)$ & $<0.9$ & $18(9.5 \%)$ & $<0.2$ \\
\hline Dalen et all & Sutureless (PS) & 78 & $1(1.2 \%)$ & $<0.9$ & $4(5.1 \%)$ & $<0.9$ \\
\hline Forcillo et all & Sutureless (PS) & 76 & 0 & $<0.3$ & $13(17 \%)$ & $<0.1$ \\
\hline Wahlers et all & RD (EI) & 158 & $1(0.6 \%)$ & $<0.9$ & $8(5 \%)$ & $<0.9$ \\
\hline Glimanov et all & Sutureless/RD (PS, EI, 3F enable) & 133 & NG & $/$ & $6(4.5 \%)$ & $<0.9$ \\
\hline Nguyen et all & Sutureless (PS) & 25 & $3(12 \%)$ & $<0.05$ & $5(20 \%)$ & $<\mathbf{0 . 0 2}$ \\
\hline Our series & $\begin{array}{c}9 \text { stitches technique (isolated AVR } \\
\text { combined \& redo procedures) }\end{array}$ & 63 & $1 * *(1.5 \%)$ & $/$ & $2 *(3 \%)$ & $/$ \\
\hline
\end{tabular}

PV Paravalvular leak PM Pacemaker implantation NG Not given PS Perceval S EI Edwards Intuity

RD Rapid deployment

* The pacemaker control after 2 months showed a normal conduction in 1 patient

** 1st patient of the series, bicuspid aortic valve

Our results suggest that our procedure is technically feasible and safe and it is associated with satisfactory hemodynamic and clinical results.

However, follow-up is limited, and no conclusion can be drawn regarding the long-term results.

\section{Conclusions}

This study demonstrates that the 9 stitches technique is a safe and acceptable treatment for critical aortic valve disease

The potential advantages of this procedure can be a shorter aortic cross-clamp (ACC) and cardiopulmonary bypass (CPB) time; especially in combined procedures. It can be used without increasing the risk of paravalvular leak.

Further investigation and data collection will allow the assessment of valve performance over a more extended period

\section{Conflict of Interest}

The authors have declared that no conflict of interest exists.

\section{REFERENCES}

[1] Pisano C, Totaro P, Triolo OF. Advantages of Minimal Access Versus Conventional Aortic Valve Replacement in Elderly or Severely Obese Patients. Innovations March/April 2017

[2] Raja SJ, Benedetto U. Minimal access aortic valve replacement via limited skin incision and complete median sternotomy. J Thorac Dis 2013.

[3] Phan K, Zhou JJ, Niranjan N, Di Eusanio M, Yan TD.
Minimally invasive reoperative aortic valve replacement a systematic review and meta-analysis. Ann Cardiothorac Surg 2015.

[4] Phan K, Xie A, Tsai YC, Black D, Di Eusanio M, Yan TD. Ministernotomy or minithoracotomy for minimally invasive aortic valve replacement a Bayesian network meta-analysis pdf. Ann Cardiothorac Surg 2015.

[5] Moustafa MA, Abdelsamad AA, Zakaria G, Omarah MM. Minimal vs Median Sternotomy for Aortic Valve Replacement. ASIAN CARDIOVASCULAR \& THORACIC ANNALS 2007.

[6] Mihaljevic T, Cohn LH, Unic D, Aranki SF, Couper GS, and Byrne JG. One Thousand Minimally Invasive Valve Operations Early and Late Results. Annals of Surgery 2004; 240(3).

[7] Glauber M, Ferrarini M, Miceli A. Minimally invasive aortic valve surgery state of the art and future directions. Ann Cardiothorac Surg 2015.

[8] Furukawa N, Kuss O, Aboud AS, M., et al. Ministernotomy versus conventional sternotomy for aortic valve replacement matched propensity score analysis of 808 patients. European Journal of Cardio-Thoracic Surgery 2014.

[9] Fattouch K, Moscarelli M, Del Giglio M, et al. Non-sutureless minimally invasive aortic valve replacement: mini-sternotomy versus mini-thoracotomy: a series of 1130 patients. Interactive CardioVascular and Thoracic Surgery 2015 .

[10] Brown ML, McKellar SH, Sundt TM, and Schaff HV. Ministernotomy versus conventional sternotomy for aortic valve replacement A systematic review and meta-analysis. The Journal of Thoracic and Cardiovascular Surgery 2009.

[11] Bakir I, Casselman FP, Wellens F, et al. Minimally Invasive Versus Standard Approach Aortic Valve Replacement: A Study in 506 Patients. Ann Thorac Surg 2006.

[12] Bajwa G, Mihaljevic T, Gillinov Ma, Svensson L. Minimally Invasive Aortic Valve Replacement. operative techniques in thoracic and cardiovascoular surgery 2010.

[13] Aris A, Camara ML, Montiel J, Delgado LJ, Galan J, and Litvan H. Ministernotomy Versus Median Sternotomy for Aortic Valve Replacement: A Prospective, Randomized 
Study. Ann Thorac Surg 1999.

[14] Aris A, Camara ML, Montiel J, Delgado LJ, Gala'n J, and Litvan H. Ministernotomy Versus Median Sternotomy for Aortic Valve Replacement: A Prospective, Randomized Study. Ann Thorac Surg 1999.

[15] Alassar Y, Yildirim Y, Pecha S, Detter C, Deuse T, and Reichenspurner H. Minimal access median sternotomy for aortic valve replacement in elderly patients. Journal of Cardiothoracic Surgery 2013.

[16] Vola M, Campisi S, Gerbay A, et al. Sutureless Prostheses and Less Invasive Aortic Valve Replacement Just an Issue of Clamping Time. Ann Thorac Surg 2015.

[17] Santarpino G, Pfeiffer S, Schmidt J, Concistrè G, and Fischlein T. Sutureless Aortic Valve Replacement First-Year Single-Center Experience. Ann Thorac Surg 2012.

[18] Chang G, Thang Vu D, Leok K, Teoh K, Kah L, Kofi T. sutureless aortic valve implantation first experience in Asia. Singapore Med J 2014.

[19] Sampaio Orismar R, Costa da Silva F Jr., Santana de Oliveira et al. Postoperative Outcome of Patients with Prosthetic Valve Leak. Arq Bras Cardiol 2009; 93(3) : 262-267

[20] Kliger C, Eiros R, Isasti G et al. Review of surgical prosthetic paravalvular leaks: diagnosis and catheter-based closure. Eur Heart J (2013) 34 (9): 638-649

[21] Nguyen A, Fortin W, Mazine A, et al. feasibility and outcomes of sutureless aortic valve replacement in patients with bicuspid aortic valved. The Journal of thoracic and cardiovascular surgery 2015.

[22] Tabata M, Umakanthan R, Cohn LH, et al. Early and late outcomes of 1000 minimally invasive aortic valve operations. European Journal of Cardio-thoracic Surgery 2008.

[23] Shehada SE, Öztürk O, Wottke M, and Lange R. Propensity score analysis of outcomes Following minimal access versus conventional aortic valve replacement European Journal of Cardio-Thoracic Surgery 2015.

[24] Raja SG, Benedetto U, Amrani M. Aortic valve replacement through J-shaped partial upper sternotomy. J Thorac Dis 2013.

[25] Onur Hanedan M, Mataracı I, Yürük MA, et al. Early Outcomes of Sutureless Aortic Valves. Korean J Thorac Cardiovasc Surg 2016.

[26] Gilmanov D, Miceli A, Ferrarini M, et al. Aortic Valve Replacement Through Right Anterior Minithoracotomy: Can Sutureless Technology Improve Clinical Outcomes? Ann Thorac Surg 2014.

[27] Dunning J, Graham RJ, Thambyrajah J, Stewart MJ, Kendall SWH, and Hunter S. Stentless vs. stented aortic valve bioprostheses: a prospective randomized controlled trial. European Heart Journal 2007; 28.

[28] Dominik J, Zacek P. Heart Valve surgery. 2010.

[29] Cremer J, Schöttler J, Petzina R, Hoffmann G. stented bioprosthesis in aortic positions. Proceedings in Intensive Care and Cardiovascular Anesthesia 2012.

[30] Barreto-Filho JA, Wang Y, Dodson JA, et al. Trends in Aortic Valve Replacement for Elderly Patients in the United States, 1999-2011. JAMA 2013.

[31] Ali A, Abu-Omar Y, Patel A, et al. Valve failure following homograft aortic valve replacement: does implantation technique have an effect? European Heart Journal 2008. 